\title{
Alienígenas na sala: o que fazer com espécies exóticas em trabalhos de taxonomia, florística e fitossociologia?
}

Marcelo Freire Moro ${ }^{1,8}$, Vinicius Castro Souza ${ }^{2}$, Ary Teixeira de Oliveira-Filho ${ }^{3}$, Luciano Paganucci de Queiroz ${ }^{4}$, Claudio Nicoletti de Fraga ${ }^{5}$, Maria Jesus Nogueira Rodal ${ }^{6}$, Francisca Soares de Araújo ${ }^{7}$ e Fernando Roberto Martins ${ }^{1}$

Recebido em 15/10/2012. Aceito em 29/11/2012

\begin{abstract}
RESUMO
(Alienígenas na sala: o que fazer com espécies exóticas em trabalhos de taxonomia, florística e fitossociologia?): A presença cada vez mais disseminada de organismos exóticos (muitos dos quais se tornam invasores) nas diferentes regiões do planeta levou ao surgimento de uma linha de pesquisa na ecologia voltada às invasões biológicas. E para permitir a comunicação entre autores também foi desenvolvido um arcabouço terminológico. Mas, apesar disso, a terminologia relativa às bioinvasões tem sido ignorada por boa parte dos botânicos no Brasil. Há uma boa dose de confusão entre botânicos sobre o que seja uma espécie exótica, naturalizada, invasora, daninha e ruderal, levando ao uso inconsistente da terminologia. Além disso, diferentes autores têm adotado posturas praticamente opostas ao lidar com espécies exóticas em suas áreas de estudo, seja na preparação de tratamentos taxonômicos, seja na publicação de levantamentos florísticos e fitossociológicos. Enquanto alguns pesquisadores incluem em floras mesmo espécies cultivadas que não se reproduzem, outros excluem plantas invasoras comuns e conspícuas. Nós apresentamos aqui, em português, os principais conceitos relativos ao tema da bioinvasão e chamamos a atenção dos autores brasileiros para a necessidade de utilizar de modo consistente o arcabouço terminológico já existente na literatura. Também propomos a adoção de rótulos claros para informar quais espécies são exóticas na área estudada, diferenciando-as das nativas, e sugerimos critérios para ajudar botânicos a decidirem quando uma planta exótica deve ou não ser incluída em tratamentos taxonômicos ou levantamentos de florística.
\end{abstract}

Palavras-chaves: Conceitos, espécies exóticas, invasões biológicas, floras

\begin{abstract}
(Aliens in the room: what to do with exotic species in taxonomic, floristic and phytosociological studies?): The ever-growing presence of exotic organisms (many of which become invasive) throughout the planet has led to the emergence of biological invasions as a field of study within ecology. To enable communication between scientists in this field, a terminology has developed. However, this terminology has been ignored by many botanists in Brazil where there is confusion regarding definition of exotic, naturalized, invasive, weed and ruderal species, leading to inconsistent use of the concepts. Moreover, different authors have adopted antagonistic positions when dealing with exotic species existing in their study areas, either in the preparation of taxonomic treatments or in floristic and phytosociological surveys. While some authors include in floras cultivated, non reproducing species, others exclude even widespread and common invasives. We present here, in Portuguese, the main concepts related to the theme of bioinvasion and draw the attention of Brazilian authors to the necessity for consistent use of the terminological framework available for biological invasions. We also propose that authors should clearly label exotic plants reported in their work, differentiating exotics from native species. Finally, we suggest criteria to help botanists decide when exotic plants should or should not be included in taxonomic treatments or in floristic surveys.
\end{abstract}

Key words: Concepts, exotic species, biological invasions, floras

\footnotetext{
${ }^{1}$ Universidade Estadual de Campinas, Instituto de Biologia, Departamento de Biologia Vegetal, Campinas, SP, Brasil

${ }^{2}$ Universidade de São Paulo, Escola Superior de Agricultura Luiz de Queiroz/USP, Departamento de Ciências Biológicas, Herbário ESA, Piracicaba, SP, Brasil

${ }^{3}$ Universidade Federal de Minas Gerais, Instituto de Ciências Biológicas, Departamento de Botânica, Belo Horizonte, MG, Brasil

${ }^{4}$ Universidade Estadual de Feira de Santana, Departamento de Ciências Biológicas, Feira de Santana, Bahia, Brasil

${ }^{5}$ Instituto de Pesquisas Jardim Botânico do Rio de Janeiro, Rio de Janeiro, RJ, Brasil.

${ }^{6}$ Universidade Federal Rural de Pernambuco, Departamento de Biologia, Área de Botânica, Laboratório de Fitossociologia, Recife, PE, Brasil

${ }^{7}$ Universidade Federal do Ceará, Centro de Ciências, Departamento de Biologia, Fortaleza, CE, Brasil

${ }^{8}$ Autor para correspondência: bio_moro@yahoo.com.br
} 
Marcelo Freire Moro, Vinicius Castro Souza, Ary Teixeira de Oliveira-Filho, Luciano Paganucci de Queiroz, Claudio Nicoletti de Fraga, Maria Jesus Nogueira Rodal, Francisca Soares de Araújo e Fernando Roberto Martins

\section{Introdução}

Espécies exóticas invasoras são reconhecidas como uma das principais causas de perda de biodiversidade no planeta, e dado o aumento global no fluxo de pessoas e bens a tendência é que espécies potencialmente invasoras sejam cada vez mais disseminadas, ampliando seus impactos ambientais (Vitousek et al. 1997; Secretariado da Convenção sobre Diversidade Biológica 2006; Gardener et al. 2012). Os motivos pelos quais uma espécie exótica é introduzida em uma área são muito variáveis, indo do acidental (e.g. organismos transportados em água de lastro de navios e sementes de plantas daninhas transportadas junto com grãos) ao intencional (árvores cultivadas com fins silviculturais e plantas ornamentais) (e.g Harrington et al. 2003; Silva \& Souza 2004).

É verdade que nem todas as espécies exóticas se tornam invasoras e nem todas as invasoras causam grandes problemas ambientais (veja uma discussão no tópico de "Resultados e discussão" mais abaixo), mas dado o grande impacto ecológico e econômico que várias das espécies invasoras geram, o tema atingiu projeção no meio científico e político (Secretariado da Convenção sobre Diversidade Biológica 2006; Gardener et al. 2012). A moderna preocupação com os impactos gerados por organismos exóticos tem seu marco na publicação de Charles Elton (1958 - The ecology of invasions by animals and plants), embora naturalistas anteriormente, como o próprio Charles Darwin no livro com suas viagens no navio Beagle, de 1839, já tivessem deixado observações sobre espécies invasoras nos seus escritos. Desde então, uma rica literatura em torno do tema foi produzida e muitos estudos de caso demonstraram os impactos gerados por espécies invasoras (e.g. Andrade et al. 2009; Abreu \& Rodrigues 2010; Abreu \& Durigan 2011), e as dificuldades práticas, econômicas e institucionais na aplicação dos métodos de controle, erradicação e biossegurança (e.g. Starfinger et al. 2003; Gardener et al. 2010; Gardener et al. 2012). Mas embora o tema da bioinvasão, por si só, tenha crescido em uma área própria dentro da ecologia, taxonomistas e fitossociologistas em grande medida não estão cientes da terminologia aplicada a esta área de pesquisa. Naturalmente, as definiçõos associadas a um dado termo podem variar de autor para autor, mas em um trabalho que reuniu alguns dos principais pesquisadores de bioinvasão do mundo (Richardson et al. 2000), foram propostas definições claras para o campo da bioinvasão, como um arcabouço relativamente bem estabelecido para lidar com os conceitos. Uma segunda versão desse texto também foi publicada na revista Taxon buscando divulgar melhor os conceitos entre taxonomistas e atingir uma melhor "comunicação entre taxonomistas e ecologistas" (Pyšek et al. 2004).

Entretanto, essas definições permanecem praticamente ignoradas tanto pelos taxonomistas quanto fitossociologistas (e curiosamente por uma parte dos ecólogos) no Brasil, resultando na adoção de termos pouco claros ou mesmo incorretos por parte dos botânicos. Outra inconsistência é a postura que floras e catálogos adotam diante de espécies exóticas. Algumas floras e catálogos incluem mesmo plantas cultivadas, enquanto outras excluem do tratamento até invasoras amplamente disseminadas. Assim, o objetivo deste artigo é fazer uma avaliação sobre como as espécies exóticas vem sendo tratadas na literatura botânica brasileira e chamar a atenção, em língua portuguesa, para as definições utilizadas na literatura internacional, defendendo a necessidade de alinhar a terminologia aplicada no Brasil com a internacional. Por fim, fazemos sugestões sobre como lidar com espécies exóticas em trabalhos taxonômicos, florísticos e fitossociológicos.

\section{Metodologia}

Avaliamos o tratamento dado às espécies exóticas na literatura botânica no Brasil, focando especialmente em catálogos de espécies e floras estaduais, além de artigos de florística e/ou fitossociologia. Nosso objetivo não é fazer uma revisão ou uma síntese sobre o tema, mas apenas o de mostrar que, em primeiro lugar, há grande heterogeneidade de posturas diante das espécies exóticas na literatura botânica do Brasil, desde tratamentos que incluem em floras espécies cultivadas até trabalhos que se omitem de fazer qualquer referência às espécies exóticas, mesmo que invasoras altamente disseminadas e conspícuas. Também avaliamos o modo como a terminologia relativa à bioinvasão é utilizada, chamando a atenção para o fato de que os conceitos vêm sendo aplicados de modo pouco claro (como o uso do termo "subespontânea" para qualquer exótica encontrada fora de cultivo, incluindo exóticas ocasionais, naturalizadas e invasoras - ver "Terminologia” mais abaixo) ou mesmo errôneo (confusão entre os conceitos de "planta invasora" e "planta daninha").

Consultamos diversos artigos de florística e fitossociologia e catálogos e floras regionais e estaduais e avaliamos como cada estudo lidava com as espécies exóticas. Selecionamos oito espécies exóticas invasoras amplamente dispersas no território brasileiro e averiguamos como elas são tratadas em quatro obras de referência: o Catálogo de Plantas e Fungos do Brasil (Forzza et al. 2010); o Checklist das Plantas do Nordeste Brasileiro (Barbosa et al. 2006); o catálogo Plantas da Floresta Atlântica (Stehmann et al. 2009); e o Checklist das Spermatophyta do Estado de São Paulo, Brasil (Wanderley et al. 2011).

Por fim, apresentamos em português a terminologia utilizada na literatura internacional (Richardson et al. 2000; Pysek et al. 2004) e fazemos uma sugestão sobre como botânicos podem lidar com espécies exóticas encontradas em suas áreas de pesquisa. Os conceitos defendidos aqui são aqueles propostos por Richardson et al. (2000) e Pysek et al. (2004), os quais são amplamente adotados na literatura internacional de bioinvasão, mas diversas outras obras internacionais e nacionais (e.g. Aronson et al. 2011) também foram consultadas na preparação deste estudo. 


\section{Resultados e discussão}

É importante que as definições sobre o que é uma espécie daninha, exótica, naturalizada e invasora estejam claras para os botânicos. Obviamente, é possível que conceitos diferentes sejam associados a um mesmo termo e especificamente no caso da bioinvasão a não adoção de conceitos claros tornou a literatura um tanto confusa (Richardson et al. 2000). Advogar um ou outro conceito é sempre uma tarefa difícil, porque as opiniões divergem, mas dado a razoabilidade e ampla aceitação das definições propostas por Richardson et al. (2000) e Pysek et al. (2004), cremos que os autores fornecem uma base adequada para lidar com o tema. Assim, recomendamos a adoção desse sistema, o qual apresentamos aqui em português, chamando desde já a atenção de que os termos planta exótica, naturalizada, invasora e daninha não são sinônimos:

\section{Terminologia}

Espécie nativa (native species). É uma espécie que ocorre naturalmente em um dado local, devendo sua presença na área à sua própria capacidade dispersiva e competência ecológica. Espécies nativas estão em dado local ou porque evoluíram ali, ou porque evoluíram em outros locais e se dispersaram sem ajuda humana até atingir sua atual distribuição geográfica. Em suma, uma espécie é considerada nativa de dado local se não tiver sido levada para lá pelos seres humanos. Quando uma nova espécie evolui em dado local, ela eventualmente poderá ampliar naturalmente sua distribuição geográfica, tornando-se nativa das áreas geográficas onde puder chegar por conta própria ou com ajuda de organismos mutualistas não humanos. Para espécies nativas que ampliam sua distribuição geográfica, o termo espécie expansiva, migrante ou colonizadora (explicado mais abaixo) é apropriado. Outros sinônimos para espécies nativas são espécies indígenas ou autóctones. Por vezes, usam-se fronteiras geopolíticas para definir um grupo de espécies nativas (e.g. espécies nativas do Brasil), mas do ponto de vista biogeográfico o nome nativo está vinculado às áreas e ecossistemas onde uma planta naturalmente ocorre. Claro que para fins de listagem as fronteiras geopolíticas podem ser utilizadas de referência, mas em relação às definições ecológicas, uma espécie da Caatinga levada para cultivo na Amazônia deve ser considerada exótica. Embora as fronteiras geográficas sirvam como referência para a compreensão humana, ao lidar com estudos florísticos os pesquisadores devem avaliar se uma espécie é nativa daqueles ecossistemas que estão sendo estudados, e não das fronteiras geopolíticas.

Espécie exótica (exotic species; alien species). Espécie que não ocorreria naturalmente em uma dada região geográfica sem o transporte humano (intencional ou acidentalmente) para a nova região. Os termos alienígena, alóctone, introduzida, não nativa e não indígena são sinônimos. Segundo a edição de 1975 do Novo Dicionário Aurélio de Língua
Portuguesa, alienígena é o "que ou quem é de outro país; estrangeiro" e exótico é o "que não é indígena; estrangeiro", portanto, ambos os termos são igualmente adequados para indicar espécies trazidas pelo homem para um dado local, mas que, antes, não ocorriam naturalmente naquele local. $\mathrm{O}$ termo espécie exótica, entretanto, tornou-se mais difundido na literatura em português, sendo a escolha mais comum. Apesar disso, o termo alienígena é conceitualmente igual a exótico e é bastante utilizado na literatura em inglês. Boa parte das exóticas que são introduzidas em uma nova região não se reproduzem e não têm qualquer impacto ecológico (Richadson et al. 2000), mas algumas se reproduzem e atingem diferentes graus de naturalização, desde plantas que se tornam apenas exóticas casuais até invasoras agressivas (ver abaixo).

a) Espécies exóticas casuais (casual alien species). Algumas espécies exóticas, ao chegarem a uma nova região, conseguem se tornar reprodutivas (sexual ou vegetativamente) e eventualmente produzir descendentes. Entretanto, várias dessas espécies não mantêm uma população viável no ambiente sem a intervenção humana direta e, se não forem ativamente cultivadas, acabam por extinguir-se do local de introdução (em contraste com espécies exóticas naturalizadas, ver mais abaixo, que estabelecem populações localmente persistentes). Exóticas casuais são plantas exóticas que eventualmente se reproduzem no ambiente no qual foram introduzidas, mas não são capazes de manter uma população autônoma em longo prazo (pelo menos uma década, como uma regra prática para classificação). Neste grupo também estão as "espécies persistentes após cultivo", comuns em áreas agrícolas. Um sinônimo seria espécie exótica transiente. A literatura inglesa também traz os termos waifs, occasional escapes e persisting after cultivation (Richardson et al. 2000).

b) Espécie naturalizada (naturalized species). São espécies exóticas que conseguem se reproduzir de modo consistente no local onde foram introduzidas, de modo a estabelecer uma população autoperpetuante sem a necessidade da intervenção humana direta, mas que, entretanto, não se dispersaram para longe do local de introdução. Exemplos são plantas que produzem descendentes que se desenvolvem, tornam-se maduros e produzem novos descendentes, os quais também atingem maturidade, garantindo a perpetuação da espécie no local (segundo sugerido por Pysek et al. 2004, por pelo menos uma década), mas que, devido a limitações na dispersão ou na competência ecológica, ficam restritas a áreas próximas do local de introdução, sem ocupar novas áreas. Uma espécie invasora pode passar pelo estágio de naturalizada e se dispersar cada vez mais até se tornar invasora, e neste caso o estágio de naturalizada é apenas mais um passo no processo de bioinvasão. Entretanto, parte das espécies naturalizadas nunca se tornam invasoras de fato (Richardson et al. 2000). 
c) Espécie invasora (invasive species). São plantas exóticas que, além de conseguir reproduzir-se consistentemente e manter uma população viável autonomamente, também conseguem dispersar-se para áreas distantes do local original da introdução e lá estabelecer-se, invadindo a nova região geográfica para onde foram levadas. Espécies invasoras são um grave problema ambiental, mas nem todas as espécies invasoras geram danos realmente apreciáveis. Algumas se restringem a ocupar áreas degradadas (ver o conceito de "ruderal" mais abaixo) e não são capazes de competir com espécies nativas em áreas bem conservadas. Mas é importante lembrar que o que define se uma espécie exótica tornou-se ou não invasora é a sua capacidade de dispersão, de se espalhar na nova região e não necessariamente sua agressividade na competição com as espécies nativas (Pyšek et al. 2004). Em relação às plantas com dispersão por propágulos (e.g. sementes ou frutos) Richardson et al. (2000) propõem como distância de referência para considerar uma exótica como invasora a capacidade de se dispersar sem ajuda humana a distâncias maiores que $100 \mathrm{~m}$ do local de introdução em menos de 50 anos. Para plantas com reprodução vegetativa (crescimento de raízes, rizomas, estolões ou caules reptantes), distâncias maiores que $6 \mathrm{~m}$ em 3 anos. A despeito da existência de muitas invasoras de pequeno impacto para os ecossistemas, as quais ocorrem preferencialmente em áreas ruderais, parte das espécies invasoras é altamente agressiva, invadindo ecossistemas naturais, alterando a composição e estrutura da vegetação e ameaçando a biodiversidade nativa (a exemplo de algumas espécies de Pinus e Gramineae no Cerrado - Pivello et al. 1999; Abreu \& Durigan 2011). Richardson et al. (2000) chamam esse subgrupo de "espécies invasoras transformadora de ecossistemas" (transformers), e que em português poderiam ser chamadas de "invasoras transformadoras de ecossistemas", ou mais simplesmente de "invasoras agressivas". Mas ressaltamos que para uma espécie ser considerada invasora o ponto chave é a dispersão, e não o impacto que a espécie gera, bastando a capacidade de manter uma população e se dispersar para novas áreas para se enquadrar como planta invasora. Obviamente, para fins de manejo, os esforços de controle de espécies invasoras devem ser direcionados prioritariamente às espécies mais agressivas.

Os termos acima definem o arcabouço conceitual apresentado por Richardson et al. (2000) e Pyšek et al. (2004) e que têm sido adotados de modo amplo na literatura de bionvasão. Entretanto, no Brasil o termo "espécie subespontânea" (eventualmente também chamada de "espécie adventícea") tem sido frequentemente utilizado, embora de modo bastante impreciso, sendo aplicado para enquadrar espécies exóticas que variam desde exóticas casuais até invasoras agressivas. Especialmente, o termo subespontâneo não é comum na literatura internacional, que tem preferido naturalized ou invasive species. Assim, sugerimos substituir o uso dessa palavra por invasora ou naturalizada, a depender do grau de naturalização da espécie.
Dois outros termos precisam ser definidos com clareza para evitar o uso incorreto com que têm sido aplicados pelos botânicos no Brasil: espécies daninhas e ruderais.

Espécie daninha (weed). O termo "espécie daninha" (do inglês weed) é antropocêntrico e tem a intenção explícita de refletir uma espécie que vai contra os interesses humanos. São daninhas plantas que crescem onde não são desejadas pelas pessoas e seu uso é de sentido bastante prático, e não ecológico. Uma planta desejada em um local pode ser indesejada em outro e, nesse local indesejado, será considerada daninha. Eventualmente, na literatura taxonômica, espécies daninhas (para a agricultura) são erroneamente chamadas de invasoras. Do mesmo modo, em artigos das ciências agrárias, o termo invasora é comumente aplicado como sinônimo de daninha. Usar a palavra "invasora" para designar "daninha" é inadequado porque utiliza com outro sentido uma nomenclatura estabelecida amplamente na ecologia. O termo "planta invasora de culturas agrícolas", eventualmente também utilizado, pelo menos tem a vantagem de colocar a terminologia claramente em outro contexto, mas o termo invasor deve ser restrito sempre que possível às exóticas invasoras. E é salutar ressaltar que embora muitas plantas daninhas sejam exóticas invasoras, plantas daninhas não necessariamente são exóticas. Espécies nativas do cerrado como Andira humilis Mart. ex Benth. e Dimorphandra mollis Benth., por exemplo, são consideradas daninhas em pastagens do Brasil central por contrariar aos interesses humanos (Lorenzi 2008), mas não deveriam jamais ser chamadas de "invasoras", já que são nativas da região onde as pastagens se instalaram. Embora espécie daninha seja um termo demasiadamente antropocêntrico, tem a vantagem de receber uma definição mais restrita e não deve ser confundido com o sentido biogeográfico de espécie invasora ou exótica. "Peste" é outro sinônimo para organismos daninhos.

Espécie ruderal. Ruderais são espécies que ocorrem em ambientes altamente perturbados pela ação humana. Podendo tanto ser espécies nativas quanto exóticas. Um terreno abandonado, um local de descarte de entulhos ou uma área desmatada podem todos ser ocupados por uma comunidade de espécies ruderais, que eventualmente poderá iniciar o processo de sucessão ecológica. Enquanto o termo "daninha" se limita a espécies que afetam os interesses humanos, o termo ruderal tem uma nuance ecológica, tratando das espécies (tanto nativas quanto exóticas) resistentes aos impactos antrópicos e que ocorrem em áreas degradadas.

A ação humana se tornou uma das principais forças globais de modificação dos ecossistemas, de modo que é razoável uma nomenclatura associada aos efeitos antrópicos. Assim como a palavra "desmatamento" se aplica apenas à ação humana, e não à queda natural de árvores, os termos usados para as invasões biológicas também devem ser restringidos ao contexto da ação do homem. Uma planta que atravessa um oceano por conta própria, ou espécies que iniciam a sucessão ecológica primária (áreas novas 
disponibilizadas pelo recuo de geleiras ou pela formação de uma nova ilha) ou secundária (crescimento da vegetação em uma área desmatada) devem ser chamadas de colonizadoras. Especialmente com as mudanças climáticas induzidas pela ação humana, espécies e mesmo comunidades inteiras devem migrar das áreas de ocorrência atual para novos locais. Esse processo de migração já ocorreu em tempos geológicos passados e é diferente da ação de transporte direto de espécies pelo homem. Na literatura biogeográfica, vem sendo feito uso do termo "invasão" para o processo de migração das espécies nestas situações, mas, conforme pontua Pyšek et al. (2004), os termos migração ou expansão geográfica (range expansion) são mais adequados a estes casos. Do mesmo modo, quando uma espécie evolui em um local e se expande autonomamente para outras regiões, o termo migração ou expansão é mais apropriado. Desde que essa ampliação de ocorrência não seja resultado da ação humana direta, levando a espécie, os termos migrante, colonizadora ou espécie expansiva/expansora se aplicam melhor a esses contextos do que invasora.

Um glossário em português com termos relativos à restauração ecológica (incluindo também definições relativas às bioinvasões) pode ser encontrado em Aronson et al. (2011).

\section{Como espécies exóticas são tratadas em trabalhos taxonômicos, checklists e catálogos no Brasil}

\section{a) Trabalhos taxonômicos}

Trabalhos taxonômicos tanto no mundo quanto especificamente no Brasil têm adotado as mais variadas posturas diante das espécies exóticas existentes nas suas áreas de estudos (Pysek et al. 2004). Essas posturas também podem ser vistas na literatura brasileira. Queiroz (2009), por exemplo, optou por excluir todas as espécies que não fossem nativas, mesmo as invasoras comuns. Em outro extremo, a Flora Ilustrada Catarinense tende a incluir nos tratamentos mesmo plantas presentes apenas em estado de cultivo [e.g. Anacardium occidentale L. e Mangifera indica L. reportadas para Santa Catarina apenas como frutíferas cultivadas - Fleig (1989); Espécies ornamentais de cactos - Scheinvar (1985); e um volume especial da flora dedicado às Araucariáceas cultivadas - Reitz (1986)]. Uma posição intermediária, que consideramos adequada, é adotada na Flora Fanerogâmica do Estado de São Paulo, onde, salvo raras exceções, apenas espécies exóticas casuais, exóticas naturalizadas ou invasoras são tratadas.

A discordância sobre como lidar com plantas exóticas chega a resultar em posturas distintas dos coautores dentro de uma mesma obra, o que é crítico especialmente para obras de grande envergadura, só realizáveis com a participação conjunta de vários pesquisadores. Esse caso é ilustrado abaixo na tabela 1. Embora as oito espécies exóticas analisadas estejam presentes nas áreas abrangidas pelas quatro publicações, nenhuma delas re- portou a ocorrência de todas as oito invasoras. E dentro de uma mesma obra alguns dos coautores adicionaram e rotularam as exóticas, outros adicionam as exóticas, mas sem uma rotulação clara, e outros ainda não fizeram referência à ocorrência das invasoras nas suas famílias de especialidade.

É possível visualizar pela tabela 1 que mesmo em uma única obra os diferentes colaboradores adotam posturas díspares. A mesma diversidade de posturas diante das exóticas se reflete nas floras, onde algumas monografias incluem espécies presentes apenas em estado de cultivo, enquanto outras monografias não. Entendemos que é pouco prático incluir em tratamentos taxonômicos plantas meramente cultivada, mas também entendemos que é uma perda de informação útil excluir espécies naturalizadas e invasoras (ver também Palmer et al. 1995) e propomos que os autores incluam nos seus tratamentos todas as espécies exóticas que tenham atingido o estágio de naturalizada ou invasora. Se possível, é útil a listagem também de exóticas casuais ou persistentes após cultivo, mas sempre que uma exótica for listada, ela deve ser claramente identificada como tal.

Um exemplo para consulta é a Flora Fanerogâmica do Estado de São Paulo. No volume 1 (Poaceae - LonghiWagner et al. 2001), são tratadas espécies nativas e invasoras (chamadas de subespontâneas), a exemplo de Urochloa decumbens (Stapf) R.D.Webster, Panicum maximum Hochst. ex A.Rich. e até espécies persistentes após cultivo, como Sorghum spp. e Avena spp., mas não espécies exclusivamente cultivadas como Zea mays L. Essa postura é coerente, porque fornece o maior número possível de registros de espécies que desempenham ou têm potencial de desempenhar um papel ecológico como plantas invasoras. O mesmo ocorre no tratamento de Liliaceae e Balsaminaceae, duas famílias reportadas para o estado de São Paulo apenas pela presença das espécies invasoras Lilium formosanum Wallace e Impatiens walleriana Hook.f.. A inclusão de Talisia esculenta, reportada apenas como espécie cultivada para São Paulo na monografia das Sapindaceae, entretanto, revela como é difícil manter uma total homogeneidade de posturas ao longo de uma obra. Entretanto, de modo geral, a Flora de São Paulo objetiva tratar todas as nativas e as exóticas naturalizadas e invasoras, o que pode ser adotado como um padrão para floras no Brasil (Palmer et al. 1995; Pyšek et al. 2004). Já a Flora Ilustrada Catarinense adota o procedimento de adicionar aos tratamentos qualquer exótica presente no estado, mesmo que presentes apenas em estado de cultivo (e.g. Scheinvar 1985; Reitz 1986), o que gera a necessidade de descrever e ilustrar um volume grande de espécies extra, mesmo quando elas não têm significado ecológico, aumentando o esforço já imenso para a elaboração de uma flora (especialmente para famílias com grande número de espécies cultivadas, como Orchidaceae, Bromeliaceae, Araceae e Arecaceae). 
Tabela 1. Postura que quatro catálogos de referência para a flora brasileira adotam diante de algumas espécies invasoras presentes no território estudado. Regiões do Brasil: N - Região Norte; NE - Região Nordeste; CO - Região Centro-Oeste; SE - Região Sudeste; S - Região Sul. Domínios Fitogeográficos do Brasil: AMA Amazônia; CAA - Caatinga, CER - Cerrado; MAT - Mata Atlântica; PAN - Pantanal.

\begin{tabular}{|c|c|c|c|c|}
\hline Espécie & $\begin{array}{l}\text { Catálogo de plantas e fungos } \\
\text { do Brasil (Forzza et al. 2010) }\end{array}$ & $\begin{array}{l}\text { Checklist das Plantas } \\
\text { do Nordeste Brasileiro } \\
\text { (Barbosa et al. 2006) }\end{array}$ & $\begin{array}{l}\text { Plantas da Floresta Atlântica } \\
\text { (Stehmann } \text { et al. 2009) }\end{array}$ & $\begin{array}{l}\text { Checklist das Spermatophyta } \\
\text { do Estado de São Paulo, Brasil } \\
\text { (Wanderley et al. 2011) }\end{array}$ \\
\hline $\begin{array}{l}\text { Calotropis procera (Aiton) } \\
\text { W.T.Aiton (Apocynaceae) }\end{array}$ & $\begin{array}{l}\text { Consta, indicada como } \\
\text { "subespontânea", reportada } \\
\text { para as regiões N, NE, CO } \\
\text { e SE e para os domínios } \\
\text { fitogeográficos da AMA, } \\
\text { CAA e CER }\end{array}$ & $\begin{array}{l}\text { Não consta, } \\
\text { embora esteja presente }\end{array}$ & $\begin{array}{l}\text { Não consta, } \\
\text { embora esteja presente }\end{array}$ & $\begin{array}{l}\text { Consta, mas sem nenhuma } \\
\text { marcação indicativa de que } \\
\text { é exótica }\end{array}$ \\
\hline $\begin{array}{l}\text { Impatiens walleriana } \\
\text { Hook.f. (Balsaminaceae) }\end{array}$ & $\begin{array}{l}\text { Não consta, } \\
\text { embora esteja presente }\end{array}$ & $\begin{array}{l}\text { Não consta, } \\
\text { embora esteja presente }\end{array}$ & $\begin{array}{l}\text { Não consta, } \\
\text { embora esteja presente }\end{array}$ & $\begin{array}{l}\text { Consta, marcada } \\
\text { como "Naturalizada/ } \\
\text { subespontânea" }\end{array}$ \\
\hline $\begin{array}{l}\text { Ricinus communis } \mathrm{L} \text {. } \\
\text { (Euphorbiaceae) }\end{array}$ & $\begin{array}{l}\text { Consta, indicada como } \\
\text { "subespontânea", reportada } \\
\text { para as regiões N, NE e } \\
\text { CO e para os domínios } \\
\text { fitogeográficos da AMA e } \\
\text { MAT. }\end{array}$ & $\begin{array}{c}\text { Consta, mas sem } \\
\text { nenhuma marcação } \\
\text { indicativa de que é exótica }\end{array}$ & $\begin{array}{l}\text { Não consta, } \\
\text { embora esteja presente }\end{array}$ & $\begin{array}{l}\text { Não consta, embora } \\
\text { esteja presente }\end{array}$ \\
\hline $\begin{array}{l}\text { Leucaena leucocephala } \\
\text { (Lam.) de Wit (Fabaceae) }\end{array}$ & $\begin{array}{l}\text { Consta, indicada como } \\
\text { "subespontânea", reportada } \\
\text { para as regiões N, NE, CO } \\
\text { e SE e para os domínios } \\
\text { fitogeográficos da AMA, } \\
\text { CAA, CER e MAT }\end{array}$ & $\begin{array}{l}\text { Não consta, } \\
\text { embora esteja presente }\end{array}$ & $\begin{array}{l}\text { Não consta, } \\
\text { embora esteja presente }\end{array}$ & $\begin{array}{l}\text { Não consta, } \\
\text { embora esteja presente }\end{array}$ \\
\hline $\begin{array}{l}\text { Hyparrhenia rufa (Nees) } \\
\text { Stapf (Poaceae) }\end{array}$ & $\begin{array}{l}\text { Consta, indicada como } \\
\text { "subespontânea", reportada } \\
\text { para as regiões N, NE, CO, } \\
\text { SE e S e para os domínios } \\
\text { fitogeográficos da AMA, } \\
\text { CAA, CER, MAT e PAN }\end{array}$ & $\begin{array}{l}\text { Não consta, } \\
\text { embora esteja presente }\end{array}$ & $\begin{array}{l}\text { Não consta, } \\
\text { embora esteja presente }\end{array}$ & $\begin{array}{l}\text { Consta, marcada } \\
\text { como "Naturalizada/ } \\
\text { subespontânea" }\end{array}$ \\
\hline $\begin{array}{l}\text { Megathyrsus maximus (Jacq.) } \\
\text { B.K.Simon \& S.W.L.Jacobs (= } \\
\text { Panicum maximum Hochst. } \\
\text { ex A.Rich.) (Poaceae) }\end{array}$ & $\begin{array}{l}\text { Consta, indicada como } \\
\text { "subespontânea", reportada } \\
\text { para as regiões N, CO, SE } \\
\text { e } \mathrm{S} \text { e para os domínios } \\
\text { fitogeográficos da AMA, } \\
\text { CAA, CER, MAT e PAN }\end{array}$ & $\begin{array}{l}\text { Não consta, } \\
\text { embora esteja presente }\end{array}$ & $\begin{array}{l}\text { Não consta, } \\
\text { embora esteja presente }\end{array}$ & $\begin{array}{l}\text { Consta, marcada } \\
\text { como "Naturalizada/ } \\
\text { subespontânea" }\end{array}$ \\
\hline $\begin{array}{l}\text { Melinis repens (Willd.) } \\
\text { Zizka (Poaceae) }\end{array}$ & $\begin{array}{l}\text { Consta, indicada como } \\
\text { "subespontânea”, reportada } \\
\text { para as regiões CO, SE } \\
\text { e S e para os domínios } \\
\text { fitogeográficos do CER e MAT }\end{array}$ & $\begin{array}{l}\text { Não consta, } \\
\text { embora esteja presente }\end{array}$ & $\begin{array}{l}\text { Não consta, } \\
\text { embora esteja presente }\end{array}$ & $\begin{array}{l}\text { Consta, marcada } \\
\text { como "Naturalizada/ } \\
\text { subespontânea" }\end{array}$ \\
\hline $\begin{array}{l}\text { Oeceoclades maculata } \\
\text { (Lindl.) Lindl. (Orchidaceae) }\end{array}$ & $\begin{array}{l}\text { Consta, indicada como } \\
\text { "subespontânea", reportada } \\
\text { para as regiões N, NE, CO, } \\
\text { SE e S e para os domínios } \\
\text { fitogeográficos da AMA, } \\
\text { CAA, CER e MAT }\end{array}$ & $\begin{array}{l}\text { Consta, mas sem nenhuma } \\
\text { marcação indicativa de que } \\
\text { é exótica }\end{array}$ & $\begin{array}{l}\text { Consta, mas sem nenhuma } \\
\text { marcação indicativa de que } \\
\text { é exótica }\end{array}$ & $\begin{array}{l}\text { Consta, mas sem nenhuma } \\
\text { marcação indicativa de que } \\
\text { é exótica }\end{array}$ \\
\hline
\end{tabular}

\section{b) Exóticas em trabalhos de florística e fitossociologia}

Ao passo que em floras e catálogos estaduais/regionais foi possível checar diretamente até que ponto os autores estão excluindo propositalmente espécies exóticas, em florísticas e fitossociologias, que trabalham na escala local, é difícil saber se uma espécie não reportada estava ou não presente na área. Nunca é possível amostrar 100\% da comunidade de um local e as invasoras podem não estar presentes, ou não terem sido amostradas, ou ainda terem sido amostradas, mas excluídas das listagens por serem exóticas. Entretanto, há pelo menos a sugestão de que alguns autores optem por excluir da listagem final as espécies não nativas antes de publicar suas florísticas. Para a tese de doutorado do primeiro autor (M.F. Moro, dados inéditos) foram compilados 150 levantamentos florísticos e fitossociológicos no domínio fitogeográfico da Caatinga. Excluindo os artigos publicados mais de uma vez e as fitossociologias com tabelas truncadas, restaram 131 levantamentos, os quais trouxeram 8215 registros de plantas para a Caatinga (em cerca de 1700 espécies, após excluir sinônimos e registros indeterminados).

De 8215 registros compilados nos 131 levantamentos, apenas 57 registros $(0,69 \%)$, em 34 levantamentos $(26 \%)$, 
traziam pelo menos uma espécie exótica na listagem, somando um total de 30 exóticas reportadas. Pelo conhecimento de campo desse autor, essas exóticas variam no grau de naturalização de cultivadas persistentes a invasoras amplamente dispersas. Mas mesmo invasoras bastante comuns foram reportadas em poucos trabalhos (apenas quatro registros da quase onipresente Calotropis procera (Aiton) W.T. Aiton e nove da agressiva Prosopis juliflora (Sw.) DC.). E mesmo invasoras de áreas ruderais óbvias como Ricinus communis L. não são reportadas sequer uma única vez. Considerando que uma porcentagem razoável dos levantamentos compilados foram estudos feitos em áreas com vegetação secundária, agroecossistemas ou caatinga degradada, seria esperado mais registros pelo menos das invasoras comuns em áreas ruderais, as quais são amplamente dispersas. Isso sugere que uma parte dos autores esteja excluindo as plantas exóticas das suas listagens antes da publicação. Com isso, perde-se a oportunidade de saber quais são e onde estão as espécies invasoras que ocupam dada região. Tendo o registro dessas espécies nos artigos de florística (e nas coletas depositadas em herbário que devem acompanhar esses artigos - ver um protocolo de métodos florísticos e fitossociológicos em Moro \& Martins 2011) seria possível mapear a distribuição das invasoras, informação essa que é perdida se essas plantas são intencionalmente subamostradas.

Outro ponto importante é sobre o modo como as exóticas são rotuladas em artigos de florística. Muitos trabalhos de florística/fitossociologia reportam as espécies invasoras sem nenhuma nota ou marcação para informar ao leitor que aquela não é uma espécie nativa. Para botânicos experientes pode ser bastante claro quais espécies são ou não nativas, mas pensando no acesso do artigo por um público geral (ou por novos pesquisadores), é bastante útil informar quais as espécies da lista são exóticas. Assim, sugerimos marcar as exóticas presentes nas listagens (e.g. Moro et al. 2011; Castro et al. 2012) para informar ao leitor quais espécies da lista não são nativas, procedimentos esses já sugeridos em Moro \& Martins (2011), junto com outros procedimentos gerais para levantamentos florísticos e fitossociológicos.

\section{Sugestão sobre como lidar com espécies exóticas em estudos florísticos, fitossociológicos e taxonômicos}

Cremos que há dois grupos de espécies exóticas que precisam ser considerados nos levantamentos botânicos: 0 das exóticas meramente cultivadas e o das naturalizadas em algum grau. O número de plantas cultivadas em um país pode ser bastante elevado. Lorenzi \& Souza (2008) listam uma seleção de mais de 1.000 espécies ornamentais cultivadas no Brasil. Na Europa, mais de 12.000 espécies são comercialmente disponíveis para cultivo (Cullen et al. 2011), com mais de 70.000 espécies, formas, variedades e cultivares disponíveis comercialmente só no ano de 2012 para o Reino Unido (Armitage et al. 2012). Se pensarmos nas espécies presentes em jardins, mas que não são mais comercializadas, ou cultivadas apenas por colecionadores, temos um conjunto de espécies intratável para floras já sobrecarregadas com a estonteante diversidade tropical. Neste sentido, é mais razoável deixar o registro de plantas cultivadas a obras específicas sobre o tema (e.g. Lorenzi \& Souza 2008; Cullen et al. 2011).

Apesar disso, a capacidade virtualmente ilimitada de armazenamento de informações nos modernos bancos de dados e a possibilidade de reorganizar os dados da forma como se deseje abrem novas opções. A Lista de Espécies da Flora do Brasil (Forzza et al. 2012), por exemplo, aceita que se inclua no banco de dados, além de espécies nativas e "subespontâneas", espécies exóticas cultivadas. Quando se faz uma consulta ao banco de dados através da interface web, é possível obter apenas a lista de nativas, apenas a lista de "subespontâneas" (que a depender do autor tem um sentido que varia de "exótica casual" a "invasora transformadora de ecossistemas") ou apenas de "cultivadas". Do mesmo modo, ao se contabilizar quantas espécies há em território nacional, é possível manejar o banco de dados para isolar facilmente as cultivadas (e/ou as invasoras) das análises, de modo que a presença de plantas cultivadas em listagens eletrônicas não é um problema (desde que se rotulem explicitamente essas espécies como cultivadas). Para publicações impressas, caso se deseje adicionar plantas cultivadas, sugerimos apresentá-las em uma seção separada do trabalho. Lorenzi et al. (2004) pode ser usado como um modelo interessante de apresentação de dados, em que as espécies nativas são apresentadas primeiro, e as exóticas são colocadas em uma seção separada da obra, tornando clara a distinção. Sano et al. (2008), no seu checklist de espécies do Cerrado, também adotam o mesmo procedimento e colocam as espécies invasoras em uma listagem separada dentro do trabalho. Embora os autores tenham adotado conceitos imprecisos do que é uma espécie exótica, ruderal e invasora, o procedimento de separar as listagens das plantas nativas daquela das não nativas da área de pesquisa é uma postura adequada para obras impressas, ao passo que para banco de dados, que podem ser reorganizados do modo como o consulente desejar, o passo fundamental é o de rotular claramente as espécies de acordo com sua origem e grau de naturalização.

Considerando que o grau de naturalização de uma exótica é um gradiente que vai de exóticas que não se reproduzem até invasoras altamente agressivas (Richardson \& Pyšek 2012), sugerimos registrar na amostragem apenas aquelas que tenham atingido o estágio de naturalizada ou de invasora (ver definições acima), eventualmente de exóticas casuais, caso os autores considerem apropriado (e tiverem disponibilidade de fazer os tratamentos para elas). Neste sentido, é interessante buscar seguir as definições adotadas na literatura internacional e apresentadas aqui e buscar rotular no trabalho o estágio de naturalização que a espécie atingiu na área de estudos, de modo a maximizar a utilidade da informação (Richardson \& Pyšek 2012). Advogamos o abandono de termos imprecisos como "subespontânea" pelos termos melhor definidos sugeridos por Richardson et al. (2000), citando, sempre que possível, que os concei- 
tos adotados foram os apresentados por esses autores. Ao constatar que uma exótica se reproduz, o botânico pode estar inseguro sobre o grau de naturalização da planta. $\mathrm{Na}$ dúvida, consideramos que é melhor fazer o registro da espécie, rotulando-a claramente como exótica e deixando a observação de que a reprodução em campo foi observada, mas que o status de naturalização é ainda incerto.

\section{a) Como rotular espécies exóticas em floras, florísticas e fitossociologias}

Idealmente, os autores devem adotar os conceitos seguidos pela maioria da literatura internacional e podem tentar avaliar o grau de naturalização de cada espécie registrada, informando se ela é uma exótica casual, naturalizada ou invasora. Em florísticas ou fitossociologias, essa informação pode vir logo ao lado do nome científico, na própria lista de espécies, marcando as plantas exóticas com um símbolo ou escrevendo essa informação ao lado do nome da planta (e.g. Moro et al. 2011; Castro et al. 2012). Alternativamente, os autores podem preferir apresentar as plantas nativas e exóticas em tabelas separadas dentro do artigo, o que também torna clara a distinção. Em floras, além de informar no texto sobre o status exótico de uma espécie, gênero ou família, os autores podem associar a informação já ao lado do nome do táxon exótico nas chaves e cabeçalhos, de modo a ficar claro que a espécie não é nativa.

Colocamos abaixo exemplos sugeridos de formatação para identificar claramente táxons exóticos em trabalhos de taxonomia. Mais informações sobre a espécie e as observações que conduziram à classificação da espécie em dado grau de naturalização podem ser fornecidas na descrição:

Balsaminaceae (família exótica para o Brasil)

Impatiens (gênero exótico para o Brasil)

Euphorbiaceae

Impatiens walleriana Hook.f. (espécie invasora) Ricinus (gênero exótico para o estado de Santa Catarina)

Ricinus communis $\mathrm{L}$. (espécie invasora em áreas degradadas no estado de Santa Catarina)

Poaceae

Avena (gênero exótico para o estado de São Paulo)

Avena sativa L. (espécie exótica casual para o estado de São Paulo)

Poaceae

Hyparrhenia

Hyparrhenia rufa (Nees) Stapf (espécie invasora no Distrito Federal)

\section{Conclusões}

Saber quais exóticas estão presentes em uma dada região geográfica é útil. Tanto para programas de controle de exóticas, quanto em meta-análises. Assim, sempre que o botânico prepara uma flora, florística ou fitossociologia da área onde é conhecedor, ele deve rotular claramente quais das espécies listadas são introduzidas e tentar avaliar o grau de naturalização [ver "Terminologia", acima, Richardson et al. (2000) e Pyšek et al. (2004)]. A não rotulação de exóticas pode, inclusive, inflar contagens de espécies de dada região ou bioma, uma vez que pessoas contabilizando o número total de espécies a partir de compilações de listagens locais, regionais ou nacionais eventualmente poderão não conseguir discernir quais espécies são exóticas em cada listagem, para excluí-las das estatísticas.

Por outro lado, registrar quais plantas invasoras estão presentes em dada área é uma informação importante e levanta interesse em várias situações, como, por exemplo, para um biogeógrafo tentando mapear a distribuição de uma invasora e correlacioná-la com dados de clima e solo ou um ecólogo trabalhando com restauração ecológica que, ao tentar controlar uma planta invasora, pode se interessar em saber onde ocorre e a quanto tempo está estabelecida a invasora em questão. Assim, é recomendável que os botânicos incluam em suas pesquisas as espécies naturalizadas ou invasoras, deixando um rastro na literatura que permita mapear as plantas exóticas no tempo e no espaço. Até o momento o modo como plantas exóticas têm sido tratadas na literatura nacional é bastante inconsistente, mesmo dentro de uma mesma obra (ver tabela 1) e os botânicos de um modo geral parecem não estar cientes da terminologia aplicada pelo ecólogos ao processo de bioinvasão. Seria salutar um alinhamento da terminologia nacional com a internacional e um pouco mais de homogeneidade na lida com os organismos invasores. Esperamos ter contribuído neste sentido, chamando a atenção dos botânicos para a terminologia e propondo um procedimento coerente sobre como lidar com espécies naturalizadas e invasoras: listar sempre, e rotular claramente também.

\section{Agradecimentos}

M.F. Moro agradece à Fundação de Amparo à Pesquisa do Estado de São Paulo (Fapesp) e à Coordenação de Aperfeiçoamento de Pessoal de Nível Superior (CAPES) pelas bolsas de doutorado recebidas. Os autores agradecem à Dra. Giselda Durigan, pesquisadora do Instituto Florestal de São Paulo, pelas sugestões feitas ao manuscrito e pela detalhada discussão de conceitos à Dra. Eve Lucas, do Royal Botanic Gardens, Kew, pela revisão do inglês do Abstract; a Antônio Sérgio F. Castro e Wedna Machado por lerem previamente a seção da terminologia, contribuindo para a clareza do texto.

\section{Referências Bibliográficas}

Abreu, R.C.R. \& Durigan, G. 2011. Changes in the plant community of a Brazilian grassland savannah after 22 years of invasion by Pinus elliottii Engelm. Plant Ecology \& Diversity 4: 269-278.

Abreu, R.C.R.D. \& Rodrigues, P.J.F.P. 2010. Exotic tree Artocarpus heterophyllus (Moraceae) invades the Brazilian Atlantic Rainforest. Rodriguésia 61: 677-688. 
Andrade, L.A.D.; Fabricante, J.R. \& Oliveira, F.X.D. 2009. Invasão biológica por Prosopis juliflora (Sw.) DC.: impactos sobre a diversidade e a estrutura do componente arbustivo-arbóreo da caatinga no Estado do Rio Grande do Norte, Brasil. Acta Botanica Brasilica 23: 935-943. Armitage, J.; Edwards, D., Lancaster, N.; Whitehouse, C. \& Merrick, J. 2012. RHS plant finder 2012-2013. London, Royal Horticultural Society.

Aronson, J.; Durigan, G. \& Brancalion, P.H.S. 2011. Conceitos e definições correlatos à ciência e à prática da restauração ecológica. Instituto Florestal. Série Registros (São Paulo) 44: 1-38.

Barbosa, M.R.V.; Sothers, C., Mayo, S.; Gamarra-Rojas, C. \& Mesquita, A.C. 2006. Checklist das plantas do nordeste brasileiro: Angiospermas e Gymnospermas. Brasília, Ministério de Ciência e Tecnologia.

Castro, A.S.F.; Moro, M.F. \& Menezes, M.O.T. 2012. O Complexo Vegetacional da Zona Litorânea no Ceará: Pecém, São Gonçalo do Amarante. Acta Botanica Brasilica 26: 108-124.

Cullen, J.; Knees, S.G. \& Cubey, H.S. 2011. The European garden flora, flowering plants: a manual for the identification of plants cultivated in Europe, both out-of-doors and under glass. Volumes I, II, III, IV and V. Cambridge, Cambridge University Press.

Elton, C.S. 1958. The ecology of invasions by animals and plants. London, Methuen.

Fleig, M. 1989. Anacardiáceas. In: Reitz, R. (Ed.), Flora Ilustrada Catarinense. Itajaí, Herbário Barbosa Rodrigues.

Forzza, R.C.; Stehmann, J.R.; Nadruz, M.; Filardi, F.L.R.; Costa, A.; Carvalho Jr., A.A.; Peixoto, A.L.; Walter, B.M.T.; Bicudo, C.; Moura, C.W.N.; Zappi, D.; Costa, D.P.; Lleras, E.; Martinelli, G.; Lima, H.C.; Prado, J.; Baumgratz, J.F.A.; Pirani, J.R.; Sylvestre, L.S.; Maia, L.C.; Lohmann, L.G.; Paganucci, L.; Alves, M.V.S.; Silveira, M.; Mamede, M.C.H.; Bastos, M.N.C.; Morim, M.P.; Barbosa, M.R.; Menezes, M.; Hopkins, M.; Evangelista, P.H.L.; Goldenberg, R.; Secco, R.; Rodrigues, R.S.; Cavalcanti, T.; Souza, V.C. 2012. Lista de Espécies da Flora do Brasil 2012. Disponível em http://floradobrasil.jbrj.gov.br. (Acesso em 1/10/2012).

Forzza et al., R.C. 2010. Catálogo de plantas e fungos do Brasil, Volumes I e II. Rio de Janeiro, Instituto de Pesquisas Jardim Botânico do Rio de Janeiro.

Gardener, M.R., Atkinson, R. \& Rentería, J.L. 2010. Eradications and People: Lessons from the Plant Eradication Program in Galapagos. Restoration Ecology 18: 20-29.

Gardener, M.R.; Bustamante, R.O.; Herrera, I., Durigan, G.; Pivello, V.R.; Moro, M.F.; Stoll, A.; Langdon, B.; Baruch, Z.; Rico, A.; Arredondo-Nuñez, A. \& Flores, S. 2012. Plant invasions research in Latin America: fast track to a more focused agenda (in press. DOI: 10.1080/17550874.2011.604800). Plant Ecology \& Diversity.

Harrington, R.A.; Kujawski, R. \& Ryan, H.D.P. 2003. Invasive plants and the green industry. Journal of Arboriculture 29: 42-48.

Longhi-Wagner, H.M.; Bittrich, V.; Wanderley, M.G.L. \& Shepherd, G.J. 2001. Poaceae. In: Wanderley, M. das G.L., Shepherd, G.J., Giulietti, A.M. (Eds.), Flora Fanerogâmica do Estado de São Paulo. São Paulo, Hucitec.

Lorenzi, H. 2008. Plantas daninhas do Brasil: terrestres, aquáticas, parasitas e tóxicas. Nova Odessa, Plantarum.

Lorenzi, H. \& Souza, H.M. 2008. Plantas ornamentais no Brasil: arbustivas, herbáceas e trepadeiras. Nova Odessa, Plantarum.
Lorenzi, H.; Souza, H.M.; Cerqueira, L.S.C.; Costa, J.T.M. \& Ferreira, E. 2004. Palmeiras brasileiras e exóticas cultivadas. Nova Odessa, Plantarum.

Moro, M.F.; Castro, A.S.F. \& Araújo, F.S. 2011. Composição florística e estrutura de um fragmento de vegetação savânica sobre os tabuleiros pré-litorâneos na zona urbana de Fortaleza, Ceará. Rodriguésia 62: 407-423.

Moro, M.F. \& Martins, F.R. 2011. Métodos de levantamento do componente arbóreo-arbustivo. In: Felfili, J.M.; Eisenlohr, P.V., Melo, M.M. da R.F. de, Andrade, L.A. de, Meira Neto, J.A.A. (Eds.), Fitossociologia no Brasil: Métodos e Estudos de Caso. Viçosa, Editora da Universidade Federal de Viçosa.

Palmer, M.W.; Wade, G.L. \& Neal, P. 1995. Standards for the writing of floras. BioScience 45: 339-345.

Pivello, V.R.; Shida, C.N. \& Meirelles, S.T. 1999. Alien grasses in Brazilian savannas: a threat to the biodiversity. Biodiversity and Conservation 8: 1281-1294.

Pyšek, P., Richardson, D.M., Rejmánek, M., Webster, G.L., Williamson, M. \& Kirschner, J. 2004. Alien plants in checklists and floras: towards better communication between taxonomists and ecologists. Taxon 53: 131-143.

Queiroz, L.P. 2009. Leguminosas da Caatinga. Feira de Santana, Editora da Universidade Estadual de Feira de Santana.

Reitz, R. 1986. Araucariáceas cultivadas em Santa Catarina. In: Reitz, R. (Ed.), Flora Ilustrada Catarinense. Itajaí, Herbário Barbosa Rodrigues.

Richardson, D.M.; Pysek, P.; Rejmanek, M.; Barbour, M.G.; Panetta, F.D. \& West, C.J. 2000. Naturalization and Invasion of Alien Plants: Concepts and Definitions. Diversity and Distributions 6: 93-107.

Richardson, D.M. \& Pyšek, P. 2012. Naturalization of introduced plants: ecological drivers of biogeographical patterns. The New Phytologist 196: 383-96.

Sano, S.M., Almeida, S.P. \& Ribeiro, J.F. 2008. Cerrado: ecologia e flora, Volume II, Checklist com 12.356 espécies. Brasília, Embrapa.

Scheinvar, L. 1985. Cactáceas. In: Reitz, R. (Ed.) Flora Ilustrada Catarinense. Itajaí, Herbário Barbosa Rodrigues.

Secretariado da Convenção sobre Diversidade Biológica. 2006. Panorama da biodiversidade global 2. Brasília, Ministério do Meio Ambiente.

Silva, J.S.V. \& Souza, R.C.C.L. 2004. Água de Lastro e Bioinvasão. Rio de Janeiro, Interciência.

Starfinger, U.; Kowarik, I.; Rode, M. \& Schepker, H. 2003. From desirable ornamental plant to pest to accepted addition to the flora? - the perception of an alien tree species through the centuries. Biological Invasions 5: 323-335.

Stehmann, J.R., Forzza, R.C., Salino, A., Sobral, M., Costa, D.P.D. \& Kamino, L.H.Y. 2009. Plantas da Floresta Atlântica. Rio de Janeiro, Jardim Botânico do Rio de Janeiro.

Vitousek, P.M., Mooney, H.A., Lubchenco, J. \& Melillo, J.M. 1997. Human Domination of Earth's Ecosystems. Science 277: 494-499.

Wanderley, M.G.L.; Shepherd, G.J.; Martins, S.E.; Estrada, T.E.M.D.; Romanini, R.P.; Koch, I.; Pirani, J.R.; Melhem, T.S.; Harley, A.M.G.; Kinoshita, L.S.; Magenta, M.A.G.; Wagner, H.M.L.; Barros, F.; Lohmann, L.G.; Amaral, M.C.E.; Cordeiro, I.; Aragaki, S.; Bianchini, R.S. \& Esteves, G.L. 2011. Checklist das Spermatophyta do Checklist das Spermatophyta do Estado de São Paulo, Brasil. Biota Neotropica 11: 193-390. 